\title{
Research on Corporate Image Orientation
}

\author{
Hao Lv \\ Business Administration Department of Management College, Wuhan University of Technology \\ Wuhan 430070, China \\ Tel: 86-27-6268-8931Ｅ-mail: luhao@126.com
}

\begin{abstract}
Corporate image orientation is the base of corporate image planning and the first step to implement CIS (Corporate Identify System) designing. According to different schemes and design aims, strategies adopted by corporate image orientation are different. Generally speaking, we can adopt demand adaptation, reciprocal thinking, dominance prominence, reorientation and improving the occasions to implement corporate image orientation. According to their own developmental characters, situations in the market, situations of market competition, enterprises can flexibly adopt corresponding strategies in different stages of enterprise development to make the corporate image orientation clear and exact and make the corporate image impressive.
\end{abstract}

Keywords: Corporate image, Orientation, CIS

\section{Introduction}

Corporate image orientation is the base of corporate image planning and the first step to implement CIS (Corporate Identify System) designing. It grasps customers' heart world and mental endurance space and expresses corporate image through simplified information, connects corporate image with the receptive point in customers' heart world, and sequentially balances supply (corporate image) and demand (customers' intrinsic demands), transmission (effects of advertisement) and feedback (customers' reaction), and makes enterprises search their exact positions in the market and shares a place in customers' mental space based on that enterprises recognize themselves, know well opponents, understand social public mentality.

Various enterprises have different situations and their aims of corporate image orientation are different also, so in the process of corporate image orientation, they cannot but adopt different strategies of corporate image orientation. In the following text, we will put forward several effective strategies of corporate image orientation.

\section{The strategy of demand adaptation}

Image orientation of modern enterprises is inclined to catch demands and changes of customers' heart world and combine customers' interior demands with the development strategy of enterprise, and to cater for customers' mental situation or occupy customers' mental space. Therefore, many enterprises have changed traditional self-praise positioning strategy, adopted euphemistic, contrastive and neutral techniques to cater for customers' mental situation and fulfill customers' interior demands, and accordingly confirm the special position of the enterprise.

For example, US Detroit is the world famous auto manufacturing base. But when auto manufacturers in Detroit were immersed to produce heavy, long and low streamline cars, Ford developed a sort of short, fat and guly "Beetle" car. Then, if Ford blindly boasted itself and only propagandized advantages of "Beetle", it might not be accepted by customers. However, the orientation watchword of Ford was "to think over the advantage of small car". The wise advantages of this orientation were that it fulfilled consumers' interior demands to small car and catered for consumers' psychology to pursue new fashion, pursue difference and pursue surprise, and the words were simple, the mood was euphemistic to make people feel kind and finally found a space belong to Ford in customers' heart.

Otherwise, modern customers very emphasize industrial strengths of enterprise, notice science and technology contents of products, and advocate green and healthy living. So, professional concepts, high science and technology concepts and green environmental protection concepts should be wise selections in image orientation for modern enterprises.

\section{The strategy of reciprocal thinking}

To make corporate image orientation effective, we can use the method of reciprocal thinking to influence and stimulate consumers. For the strategy of reciprocal thinking, it very emphasizes that the method can not be repeated and imitate others and must start from human thinker. And the open of thinker door is influenced by human knowledge and experiences to large extents, and the information which cannot match intrinsic knowledge and experiences always is rejected, and even if it is accepted, first impressions are strongest. Investigations have proved that the market 
occupation rate of the brand which first enters customers' brain is double to the second one, four times to the third one. Therefore, simple simulation almost has no hope to succeed.

For example, many famous perfume brands such as Arpege, Chnel No.5 and so on take female as their appeal objective. Max Factor Company also positioned its perfume brand as "Just Call Maxi". And after it came into the market, it was failed before long and the president of this company also lost his position. However Reclon adopted the strategy of reciprocal thinking and succeeded by means of the pure mail brand "Reclon's Charlie", obtained female consumers' favors and became the best-selling brand in the whole world.

The 7-UP acquired success through the strategy of reciprocal thinking when Coca Cola was fashionable. Its orientation catchword is "7-UP, non-Cola". 7-UP positions its brand by "non-cola", because it takes Cola as its compare objective, and easily makes customers associate famous drinks such as "Coca Cola", and accordingly drives up its own social status. At the same time, it offers a new choice for those persons who don't like the taste of Cola. In addition, because customers always have sorts of desire to know unknown things, many customers of Cola also want to taste this new drink which dares to compare with "Coca Cola" and is different with "Coca Cola". Otherwise, this orientation also brings strong effects that advertisement can not achieve, because Coca Cola Company takes action to 7-UP because the later forms infringement because of "7-UP, non-Cola", but the recover is "7-UP". The fact is that 7-UP is carbonated drinks, and it is not Cola, because Cola is a sort of soft drinks containing caffeine, and it is not the patent name of "Coca Cola". This lawsuit arouses maximum attentions of social public, so the recover "7-UP" is also recognized by numerous customers and its well-know degree has been fully advanced. Therefore, this orientation of "7-UP" is very smart.

\section{The strategy of predominance prominence}

Nowadays, on the one hand, new material and new technology emerge in endlessly and they make the technical innovation ability of modern enterprise fully changed, on the other hand, the development of communication technology makes various information come in a continuous stream. They all offer more selectable opportunities for the development of modern enterprise and many enterprises just follow this tendency of social development to go after opportunities bringing various possibilities for success. Therefore, diversification management occurs. For the enterprise which has been in the leading status in the market, its enterprise image has hard occupied customers' special mental space by means of the charm of dominant product. Therefore, it give no cause for more criticism for enterprise to take its leading product as its bibcock to develop diversification management, develop business, increase incomes and reduce risks. However, some enterprises always forget their own advantages and image orientation when they acquire successes, and accordingly suffer undeserved failures.

A predominant enterprise should fix image predominance ever and again, and can not forget there own orientation of corporate image at any time. Though many large companies are implementing diversification management, but successful large companies are famous by their leading products. Japanese SONY is famous because of its TV, acoustics and other consumed electric products, and not its travel agency and drugstore. US General Motors is proud of the largest auto manufacturers, not other industrial products it produces. Therefore, though corporate image orientation doesn't conflict with diversification management, but the primary and secondary positions of both should have a clear limit.

Successful enterprises profit from their special predominance, and failing enterprises often meet with misfortune because of the loose of predominance. It is another key for corporate image orientation to recognize the predominance of enterprise. This sort of predominance can not be balanced by capital strength and transferred by other investment opportunities with allures. A promising entrepreneur is a spoony pursuer, and though there are many targets he deserves to pursue, but the objective he pursues is the only one that makes his enterprise figure special image in the predominant industry.

\section{The strategy of reorientation}

If the enterprise wants a sort of new concept or new product enter customers' brain, it must make former same opinion or brand image in customers' memories display old impressions and easily eliminate. It needs to research competitors and product brand image which have occupied consumers' thinkers, find out their disadvantages or weaknesses and implement reorientations. The essential aim of reorientation is to establish advantageous new order in consumers' memories, and once this order is established, competitors' old concept and old brand image will lose charm to customs, and new image of enterprise can enter customers' thinkers that are vacant.

It is a very smart method to exert the strategy of reorientation to deal with superiors. "Tylenol" had exerted this sort of "sudden thrust of the mace". When "Aspirin" was without equal as the king of easing pain, Tylenol cautioned against people "shouldn't use Aspirin" in its advertisement time after time, and pointed out Aspirin would "erode blood vessel wall", "induce hypersusceptibility reaction" and "induce concealed minim stomach and intestines bleeding", and draw Aspirin from the status of the king. Consequently, Tylenol occupied the first position in pain medicine and obtains success. 
The strategy of reorientation is a sort of evident strategy, and if it can not be used, it is easy to break law and regulations, and induce dissensions among enterprises, even lawsuit, and finally harm itself. Therefore, whether it is good law or not is the key to whether this strategy can be adopted. Since 1972, US Federal Trade Commission has allowed various manufacturers to advertise comparisons in ABC and CBS TV Net. In 1974, US Advertisement Association constitutes guidelines of comparison advertisement. In the same way, England Independent Institution also allows play comparison advertisement in its TV net. In China, the comparison advertisements are rare and there are no specific laws and regulations. Therefore, if China manufactures want to adopt the strategy of reorientation, they must be very careful to avoid entangling law dissensions.

\section{The strategy of improving the occasion}

Those enterprises in the competition have different market status which would continually change. The corporate image orientation must improve the occasions and flexibly adopt corresponding strategy according to different market status of the enterprise.

\subsection{Market leaders'orientation strategy}

How leaders position their own brand image, i.e. how they keep their first position in the industry? The best method is to enhance the class of the product and always occupy the position that can not be exceeded. For example, Coca Cola orientates itself that "only Coca Cola is the real Cola". It not only occupies the top rundle, but disallows others to invade its status.

What should leaders do when their images meet competitors' challenges? The best method is to develop new brand to suppress opponents, and if the orientation of new brand image can exert the strategy of reorientation for competitors, the effect will be very obvious.

If the image of enterprise, especially the leading image in the service industry suffers challenges, changes including changing the name of the company, shrinking connotation and magnifying extension are good approach. For example, "Eastman Kodak" was transformed to "Kodak", the Mitsubishi Electric Company was renamed to Mitsubishi, and the Kikkoman Sauce Company was changed to Kikkoman. This sort of change is not only the change of name, and it is the reorientation of image in fact, the orientation to enhance rundle, which can not only suppress competitors, but develop in larger domain in the market for the enterprise.

\subsection{Market followers' orientation strategy}

It is the orientation strategy or the position which should be adopted by the enterprise when it exactly analyzes competitive situation and confirms that it can not occupy the first in the market. When the enterprise is on the position, it should admit leaders' status and follow definite aim, and accordingly occupy the vantage point of the second in the market.

The famous example which stands in the followers' position to orientate its own image and obtains success is Avis Rent Car. After continual ten years' management losses, Avis admitted the leading status of Hertz Company in the same industry, and alleged that "in the rent car industry, we are only the second, but why people still rent our cars, because we try harder." After this orientation, in the first year, this Company made up the deficits and got surpluses, and gain 1.2 million dollars, and in the second year, it profited 2.6 million dollars, and in the third year, the return had achieved 5 million dollars. Follow makes Avis' image in customers' thinkers abut upon leaders, and produce magnified effect for potential customers. In addition, Avis makes itself under the shadow of "Hertz", which also expand someone's psychology who sympathize weaker and support weaker.

\subsection{Market challengers'orientation strategy}

The challengers' character is that they possess the quality of aggression, and they always gaze at leaders and put them at the opposite position of leaders, and once they have opportunity, they will challenge leaders' status, declare war on leaders and confront leaders. So challengers are also attackers and confrontationists. Challengers want to win opponents, for image orientation, on one hand, they must strengthen their own orientation image aiming at opponents' weakness, and build up the wallop of attack, on the other hand, they should reposition opponents and grasp opponents' weakness and depreciate opponents' images.

For example, as the importer of Russian "Stolichnaya", Pepsi Company found that most US vodkas looked that they were made in Russia, which worked huge pressures to the distribution of "Stolichnaya". Therefore, Pepsi Company decided to sweep the market by the pose of challenger. It pointed out in its advertisement, "The brand of "Samorar" is made in Pennsylvania, the brand of "Smirnoff" is made in Hartford of Connecticut, the brand of "Wolfschmidt" is made in Lawrenceburg of Indiana, and the larruping brand of "Stolichnaya" is made in Russia". The label on the bottle also was labeled that "Made in Leningrad of Russia". So Pepsi Company wined other competitors, and inaugurated wide sales market for real Russian vodka, Stolichnaya, and the sales rapidly increased. 


\section{Conclusions}

Above several sorts of corporate image orientation strategies possess their own characters. The strategy of demand adaptation takes customers' demands as its direction and is easily accepted and recognized by customers. The strategy of reciprocal thinking abounds in originality and wisdom, tries to win through newness. The strategy of predominance prominence starts from its own characters and makes the focus of orientation centralized and definite. The strategy of reorientation takes competition as its aim, and gets effect instantly. The strategy of improving the occasion pursues impersonality, and makes the orientation and the market harmonize.

For the choice of strategy, according to their own developmental characters, situations in the market, situations of market competition, enterprises can flexibly adopt corresponding strategies in different stages of enterprise development to make the corporate image orientation clear and exact and make the corporate image impressive.

\section{References}

Baiyu \& Wang, Jijian. (2003). Corporate Identify Planning. Wuhan: Wuhan University of Technology Press.

Liu, Fengjun. (2000). Brand Management Theory. Beijing: Economic Sciences Press.

Luo, Changhai. (2003). Corporate Image Theory. Beijing: Qinghua University Press.

Qiaomu. (2003). Position Setting and Policy Making. Beijing: China Commerce Press. 